\title{
MUNDIALIZAÇÃO DO CAPITAL, REFORMA DO ESTADO, PÓS-GRADUAÇÃO E PESQUISA NO BRASIL
}

\author{
João dos Reis Silva Júnior \\ Universidade Federal de São Carlos-UFSCar/CNPq \\ jr@ufscar.br \\ Fabíola Bouth Grello Kato \\ Universidade Federal de São Carlos-UFSCar \\ fabiola_kato@hotmail.com
}

\begin{abstract}
RESUMO:
O objetivo deste artigo é compreender o processo de mercantilização da universidade estatal pública brasileira e do atual processo de produção de conhecimento. Busca-se compreender este evento tal qual um processo de racionalização social, com origem no Estado reformado e como parte da herança do século XX, articulado com a mundialização do capital, que terminou como alvo da naturalização do seqüestro do fundo público pelo capital, resultando em reformas das instituições republicanas brasileiras. A universidade, não sem a contraposição de movimentos sociais, políticos e sindicais e de intelectuais, está sendo transformada em instituição tutelada. A racionalidade mercantil tornou-se o núcleo da Política com conseqüências para o pensamento intelectual mais crítico; a pesquisa sobre as políticas públicas para a educação superior; e, sobretudo, para a intensificação e mudança de paradigma da produção do conhecimento, da ciência e da tecnologia no âmbito institucional das universidades públicas brasileiras e no plano da Nação e em sua relação com a economia mundial.

Palavras-chave: Mundialização do Capital. Reforma do Estado. Reforma Universitária. Produção do Conhecimento. Valoração do Capital.
\end{abstract}

\section{GLOBALIZATION OF CAPITAL, STATE REFORM, POST-GRADUATION AND RESEARCH IN BRAZIL}

\begin{abstract}
:
The aim of this paper is to understand the process of commodification of public state university in Brazil and the actual process of knowledge production. We seek to understand this event as a process of social rationalization, with origin in the reformed State and as part of the heritage of the twentieth century, along with the globalization of capital, which ended as the target of naturalization of the kidnapping access of public fund for capital, resulting reforms of republican institutions in Brazil. The university, not without the opposition of social movements, political and trade union and intellectuals, is being transformed into a subordinate institution. The rationale for market became the core of the policy with consequences for the most critical intellectual thought, research on public policies for higher education and, above all, to intensify and shift the paradigm of knowledge production, science and technology within the institutional framework of public universities in Brazil and in terms of nation and its relationship with the world economy. Keywords: Globalization of Capital. Reform of the State. University Reform. Production of Knowledge. Valuation of Capital.
\end{abstract}


A nova configuração do capitalismo que se inaugura nos anos 1970 transcende a internacionalização da economia: trata-se de sua mundialização. Segundo François Chesnais (1996), existem três dimensões principais para a realização desse processo: intercâmbio comercial, investimento produtivo no exterior e fluxos de capital monetário, ou capital financeiro. O autor acrescenta que "as relações entre essas três modalidades de internacionalização devem ser buscadas ao nível das três formas ou ciclos da movimentação do capital, definidos por Marx: o capital mercantil; o capital produtor de valor e de mais-valia; o capital monetário ou capital-dinheiro" (CHESNAIS, 1996, p. 51).

Citando Charles-Albert Michalet, Chesnais afirma que essa abordagem permite mostrar a passagem da internacionalização da economia, com base no comércio exterior e nos fluxos de capital monetário e financeiro, para a economia mundializada, por sua vez ancorada na mundialização do capital produtor de mais-valia. O aumento do investimento externo direto (IED) e as conseqüências qualitativas daí derivadas na reorganização das economias nacionais e mundial, especialmente nas grandes corporações transnacionais provocam uma mudança no paradigma tradicional.

Segundo Michalet citado por Chesnais (1996, p. 52),

No paradigma tradicional, o capital produtivo fica colocado por fora da mundialização do capital. A transformação da economia internacional em economia mundial coincide com o fim dessa dicotomia. A mundialização do capital produtivo torna-se parte integrante da mundialização do capital. [...] mais exatamente, torna-se o centro dela.

Na década de 1980, especialmente em seu início, a mundialização do IED sofreu significativo aumento. No entanto, para além dos aspectos quantitativos do IED na economia mundial, seus aspectos qualitativos parecem realmente colocá-lo no centro da mundialização do capital. Para Chesnais (1996, p. 54), citando Henri Bourguinat, são quatro as principais razões:

Em primeiro lugar, diferentemente do comércio exterior, o IED "não tem uma natureza de liquidez imediata [...] ou diferida [...]". Não se reduz a uma transação pontual. ... Sua segunda característica é introduzir uma "dimensão intemporal" de grande importância, pois a "decisão de implantação dá origem a fluxos (produção, comércio, repatriação de lucros) que se estendem, necessariamente, por vários longos períodos". A terceira particularidade é "implicar transferências de direitos patrimoniais e, portanto, de poder econômico, sem medida comum à simples exportação". "Por último", diz Bourguinat, "existe um componente estratégico evidente na decisão de investimento da companhia. Não somente seu horizonte é sensivelmente mais amplo, como também as motivações subjacentes são muito ricas [...] a idéia de penetração, seja para depois esvaziar os concorrentes locais, seja para 'sugar' as tecnologias locais, [e a produção de conhecimento em lugares além da sede da corporação mundial] faz parte desse aspecto 'estratégico' do investimento direto e, geralmente, está inserido num processo complexo de tentar antecipar as ações e reações dos concorrentes." [grifo do autor] 
Nesse contexto de mundialização da economia, tendo como estratégia central não mais o comércio exterior e o capital financeiro, mas antes o capital produtivo por meio do IED nos moldes acima examinados por Chesnais e Bourguinat, emerge um novo paradigma de empresa, com novas estruturas corporativas, novas formas organizativas e de gestão, assentadas em nova base produtiva, possibilitadas, nesse último caso, pelas atuais tecnologias produzidas no âmbito da terceira revolução tecnológica. Afirma Chesnais (1996, p. 59-60), citando Michalet, a emergência de um "novo estilo", denominado em cujo centro encontra-se a estratégia tecno-financeira:

[...] de internacionalização baseada nos ativos intangíveis da companhia, no seu capital humano". E Michalet precisava: "A estratégia tecnofinanceira é o resultado de uma evolução das atividades das companhias no exterior, passando da produção material direta para o fornecimento de serviços. A base de sua competitividade está alicerçada na definição de um know-how e na $P \& D$. Ela tentará valorizar essa vantagem em todos os setores onde for possível aplicar suas competências tecnológicas. Com isso, ela tenderá a sair do seu setor de origem e diversificar-se em modalidades totalmente originais. Sua nova força reside em sua capacidade de montar 'operações complexas', [que] irão exigir a combinação de operadores vindos de horizontes muito diferentes: empresas industriais, firmas de engenharia, bancos internacionais, organismos multilaterais de financiamento. Destes, uns serão locais, outros estrangeiros, outros terão estatuto internacional [grifo meu].

Citando Dunning (1988), Chesnais (1996, p. 77) complementa que essas corporações teriam em seu centro identitário a "natureza e forma das relações que estabelece com outras empresas". No atual contexto da economia mundializada, ainda que o IED seja o centro dessa nova ordem econômica, a força do capital monetário ou financeiro faz-se presente na estruturação do novo paradigma corporativo acima descrito. $\mathrm{O}$ capital financeiro torna-se hegemônico e o monetarismo assume o lugar da macrogestão econômica em nível mundial, influenciando largamente as estruturas das grandes companhias mundialmente organizadas e dos Estados nacionais, tornando altamente instável as sociedades nacionais e a irracionalidade que viceja em nível planetário. [grifo do autor]

Do afirmado acima, pode-se depreender que as fronteiras entre lucro e renda tornam-se cada vez mais fluidas, com consequiências cada vez mais fortes para a consolidação do novo paradigma organizacional das grandes corporações em nível mundial, obrigando-as ao estabelecimento de relações mais consolidadas com outros grupos, empresas de variados portes em nível planetário.

Do que se pôde apreender acerca da forma como se estruturam e se organizam as empresas multinacionais de novo estilo ou as grandes corporações mundiais, elas:

1) atuam em nível mundial;

2) repassam aos seus fornecedores elementos da concepção e fabricação de componentes dos produtos, juntamente com know-how tecnológico, organizacional, gerencial, de processos de reengenharia, know-how de gestão de qualidade, etc., guardando a core organization para a corporação ou empresa multinacional de novo estilo (conhecimento objetivado em favor do capital). Promovem e financiam a transformação dos fornecedores. Constituem, a partir daí, uma relação de parcerias que lhes proporcionam 
vantagens, não por meio da comercialização de seus produtos (mas, descontos em componentes de seus produtos por tempo indeterminado, p. ex.), mas de seu know-how nas diversas áreas de trabalho, vascularizando o processo e tornando-se mais rentáveis;

3) desenvolvem atividades de rental service;

4) reestruturaram-se, nos anos 1980, por meio do IED;

5) estabelecem, por meio de parcerias, compras, fusões e joint-ventures, redes, buscando obter vantagens em suas relações com as outras empresas, organizações e instituições governamentais, universidades;

As empresas multinacionais de novo estilo tornam-se o eixo condutor da economia mundializada, sob a gestão monetária e a hegemonia do capital financeiro. Este atravessa e põe-se em torno do capital produtivo mundializado. Sua rentabilidade mundial é o objetivo maior. Como já visto, as corporações buscam vantagens predominantemente nas relações com empresas e instituições nacionais, internacionais ou multilaterais. Aqui se encontra a origem das reformas institucionais públicas realizadas nas décadas de 1980 e 1990.

Neste contexto, as universidades públicas vão-se colocando a serviço das empresas multinacionais de novo estilo e, assim, perdendo sua autonomia. Sua pauta de pesquisa é o que interessa, enquanto sua autonomia é posta em segundo plano. E o Estado nacional perde sua soberania.

Por outro lado, ao anunciar a multinacional de novo estilo, Michalet (apud CHESNAIS, 1996, p. 76-77), argumenta acerca dos seus capitais intangíveis, destacando o capital humano. Continua ele, afirmando que a "[...] estratégia tecno-financeira é o resultado de uma evolução das atividades das companhias no exterior, passando da produção material direta para o fornecimento de serviços". [grifo meu]. Enfatiza Michalet que a contribuição de sua força econômica e de competitividade encontra-se em seu próprio know-how e na $P \& D$ (o capital humano, aqui a educação básica, profissional e superior, a força de trabalho superqualificada e a produção de conhecimento são centrais).

No livro Novas faces da educação superior no Brasil (SILVA JÚNIOR; SGUISSARDI, 2001) mostra-se que, em seminário sobre reforma constitucional sob o patrocínio da Presidência da República, Luiz Carlos Bresser Pereira - que futuramente seria ministro titular do Ministério da Administração Federal e da Reforma do Estado (Mare) - defendia a tese de que o Estado moderno, social-democrata, constituir-se-ia segundo concepção defendida em seus escritos da forma que segue.

A proposta de reforma do aparelho do Estado parte da existência de quatro setores dentro do Estado: (1) o núcleo estratégico do Estado, (2) as atividades exclusivas do Estado, (3) os serviços não exclusivos ou competitivos, e (4) a produção de bens e serviços para o mercado. [...] $\mathrm{Na}$ União, os serviços não exclusivos de Estado mais relevantes são as universidades, as escolas técnicas, os centros de pesquisa, os hospitais e os museus. A reforma proposta é a de transformá-los em um tipo especial de entidade não-estatal, as organizações sociais. A idéia é transformá-los, voluntariamente, em "organizações sociais", ou seja, em entidades que celebrem um contrato de gestão com o Poder Executivo e contem com a autorização do Parlamento para participar do orçamento público. (PEREIRA, 1996, p. 286, grifo meu).

Aquele que interessa focar quer seja o núcleo dos Serviços não exclusivas do Estado "são todos aqueles que o Estado provê, mas que, como não envolvem o exercício do poder extroverso do Estado, pode ser também oferecidos pelo setor privado e pelo setor 
público-não estatal” (BRESSER PEREIRA, 1998, p.34, grifos meus). E deste setor fazem parte os serviços de educação, saúde, cultura e pesquisa científica.

Quanto da terminologia propriedade público não estatal, explicava "pública, no sentido de que se deve dedicar ao interesse 'público', de que não visa ao lucro. 'nãoestatal' porque não fazem parte do aparelho do Estado" (BRESSER PEREIRA, 1998, p.35)

Ao referir-se a um dos serviços não exclusivos do Estado, que aqui nos interessa, no caso a universidade, Bresser Pereira foi claro quanto a sua convicção sobre a definição do que ele chama de organizações sociais.

Nos Estados Unidos, todas as universidades são organizações públicas não-estatais. Podem ser consideradas 'privadas' ou 'controladas pelo Estado', mas, a rigor, não visam ao lucro e também não empregam servidores públicos. São parcialmente financiadas ou subsidiadas pelo Estado- sua face 'privada' é menor que a face 'controlada pelo Estado'-, mas são entidades independentes, controladas por juntas que representam a sociedade civil e- em posição minoritária pelo Estado. No Reino Unido, as universidades e os hospitais sempre estiveram sob o controle do Estado; agora já não é assim: hoje são 'organizações quase nãogovernamentais'. Não foram privatizadas: passaram do controle do Estado para o controle público. (BRESSER PEREIRA, 1998, p.35).

Sobre os procedimentos de transformação das universidades estatais públicas em fundações de direito privado, ou organizações sociais, o ex-ministro reiterava:

Para isso será necessário extinguir as atuais entidades e substituí-las por fundações públicas de direito privado, criadas por pessoas físicas. Desta forma, se evita que as organizações sociais sejam consideradas entidades estatais, como aconteceu com as fundações de direito privado instituídas pelo Estado, e assim submetidas a todas as restrições da administração estatal. As novas entidades receberão por cessão precária os bens da entidade extinta. Os atuais servidores públicos da entidade transformarse-ão em uma categoria em extinção e ficarão à disposição da nova entidade. $\mathrm{O}$ orçamento da organização será global; a contratação de novos empregados será pelo regime de Consolidação das Leis do Trabalho; as compras deverão estar subordinadas aos princípios da licitação pública, mas poderão ter regime próprio. $\mathrm{O}$ controle dos recursos estatais postos à disposição da organização social será feito por contrato de gestão, além de estar submetido à supervisão do órgão de controle interno e do Tribunal de Contas (BRESSER PEREIRA, 1996, p.286-287).

Aqui cabe ressaltar sobre a importância da publicação deste documento em 1995 para entender a origem das mudanças e reformas na universidade, sobretudo nas atividades de pesquisa, pois a constituição do "setor de serviços não exclusivos do Estado" permitiu a produção de um arcabouço jurídico que trouxesse em seu núcleo a racionalidade da reforma do Estado tão aclamada como necessária pelo ex-ministro Bresser Pereira, tendo a lógica do mercado como marco deste processo (SGUISSARDI; SILVA JR., 2009). Aí residiria a origem da mercantilização da universidade pública.

Importa ainda destacar que as instituições republicanas brasileiras, em suas mudanças e reformas, carregariam em seu núcleo institucional a racionalidade da reforma do Estado. Essa racionalidade é explicitada, nos termos acima, por Bresser Pereira ao referir-se aos serviços não-exclusivos do Estado ou competitivos. E, para que não pairasse 
nenhuma dúvida, o ex-ministro enfatizava que na União os mais relevantes desses serviços são os representados pelas universidades, escolas técnicas, centros de pesquisa, hospitais e museus. De fato, constituído o setor de serviços não-exclusivos do Estado ou competitivos, deu-se a possibilidade da produção de arcabouço jurídico sob a tutela do qual se reformassem as universidades.

Tinha, assim, origem a mercantilização da universidade pública e o seqüestro do fundo público pelo capital, isto é, dava-se o primeiro e decisivo passo para a mercantilização dessa instituição pública e a origem de um novo paradigma de produção de conhecimento. Cabe ressaltar, que o principal alvo de Pereira consistia na construção do "terceiro setor" do Estado e, com ele, de uma nova dimensão para o Estado: a mercantil. A dicotomia entre Estado e mercado, legal e institucionalmente, tornava-se agora uma contradição a ser administrada por associações mediadoras entre o Estado e a sociedade civil.

Decorre daí a existência de dois tipos de instituições estatais: pública e mercantil. No terceiro setor do Estado já reformado estão as universidades públicas, fundo público objetivado em conhecimento a serviço do capital nacional e mundial.

Ao longo de uma década, o que era arcabouço jurídico construído com base na reforma do Estado foi colocado em prática de forma bastante autocrática, diante de uma sociedade civil organizada por meio de organizações não-governamentais (ONGs) e do terceiro setor durante o governo de Fernando Henrique Cardoso, evento que obviamente era visto com bons olhos. A existência de serviços não-exclusivos do Estado ou competitivos abriria, naquele momento, um grande mercado no setor de serviços, que seria um largo espaço social, objeto de políticas focalizadas, que ONGs ou organizações da sociedade civil de interesse público (Oscips) e o terceiro setor (constituído por empresas prestadoras de serviços para o Estado) explorariam.

A primeira grande meta da reforma do aparelho do Estado era, para o ministro, sua flexibilização. Em segundo lugar, no plano social, sua radical descentralização por meio desses três tipos de associações. Trata-se, portanto, não de uma descentralização democrática, mas de uma desconcentração do Estado (PEREIRA, 1996, p. 8; SILVA JÚNIOR; SGUISSARDI, 2001, p. 30-32), pois todas as decisões de políticas públicas para o Brasil seriam tomadas de forma centralizada no Núcleo Estratégico do Estado e fiscalizadas pelo Setor de Serviços Exclusivos do Estado, cuja função consistiria na fiscalização e consolidação das políticas formuladas naquele núcleo.

$\mathrm{O}$ ex-ministro, por meio dos terceiro e quarto setores, institucionalizou a nova contradição entre o Estado e o mercado. Isto produziu a emergência de outras relações no âmbito do Estado: estatal/público, estatal/mercantil, privado/mercantil e privado stricto sensu, isto é, a prestação de serviços ao mercado por meio do fundo público ou não, mas para captação de recursos.

A institucionalização da dimensão estatal/mercantil criou um espaço para as relações entre o Estado e entidades da sociedade civil (ONGs, empresas do terceiro setor) para a prestação de serviços antes de natureza pública, por meio de contratos de gestão. Passou a permitir a transferência de responsabilidade do Estado para a sociedade civil e para o mercado. As universidades públicas passaram a executar atividades que antes não lhes eram pertinentes, tais como convênios com empresas privadas ou com associações de moradores para resolver problemas de violência, alfabetização de jovens e adultos, dentre outras.

$\mathrm{Na}$ dimensão estatal/mercantil encontrava-se a base para futuras ações jurídicas, em especial do Executivo, para a mudança substancial da identidade da instituição universitária pública, bem como do conteúdo e forma do trabalho do professor 
universitário e seu resultado: a produção de conhecimentos no âmbito institucional e nacional.

As parcerias público-privadas e os programas sociais estão diretamente relacionados ao terceiro setor do aparelho do Estado, isto é, aos "serviços não-exclusivos do Estado ou competitivos". Com a institucionalização deste núcleo, surge um novo modo de formulação de políticas e a universidade pública passa a ocupar posição estratégica neste cenário.

O novo paradigma traz em si a articulação de uma política universal, a econômica, e políticas focais voltadas para o social por meio de programas emergenciais sem o objetivo de uma resolução estrutural da concentração de renda e patrimônio, dos conflitos no campo, da pobreza, da fome e do trabalho escravo.

Em 2003 o então ministro da Fazenda, Antonio Palocci, produziu um longo documento (95 páginas) para o Encontro de Primavera com o FMI, nominado Política econômica e reformas estruturais ${ }^{i}$, cuja ênfase era o ajuste fiscal, em detrimento do social, no que se refere a um programa sistematizado, articulado com as diversas áreas da gestão pública nacional. O social parece que seria tratado de forma emergencial, com destaque para a educação. A prioridade era a política econômica (contenção inflacionária e ajuste fiscal) e sua construção por meio da aliança contraditória do governo com as agências multilaterais, o capital industrial brasileiro e internacional e a sociedade civil redesenhada e com novas responsabilidades, que outrora eram deveres do Estado. Isto veio ratificar a primeira leitura do lugar e das finalidades das políticas educacionais e sociais em geral no governo Lula e da nova função da instituição universitária, especialmente no que se refere à produção do conhecimento.

É importante notar que a mediação realizada pelo Ministério de Ciência e Tecnologia (MCT), via Conselho Nacional de Desenvolvimento Científico e Tecnológico (CNPq), objetiva a inclusão social e econômica a ser executada pelas entidades da sociedade civil, dentre elas a universidade, por meio da extensão. Vale destacar, ainda, que a grande maioria das ONGs é formada por professores das melhores universidades e institutos de pesquisa do país.

No entanto, no âmbito econômico houve controle da inflação, crescimento econômico a taxas altas, em cumprimento das metas pactuadas com os organismos multilaterais, e alcançou-se o upgrade de investimento conferido pela Standard \& Poor's.

No jornal Valor Online, podia-se ler em junho de 2008 a manchete "Investimento estrangeiro direto aumenta 33\% no ano e atinge US\$ 14 bi". Traduza-se: rápida entrada do capital produtivo, ou seja, de capital produtor de valor. Em outros termos, "nos cinco primeiros meses de 2008, foi registrada a entrada líquida de US\$13,984 bilhões (2,44\% do PIB), um aumento de $32,75 \%$ sobre os US\$ 10,534 bilhões verificados em intervalo equivalente de 2007 (2\% do PIB)" (LULA, 2008). Aqui é importante lembrar o que se escreveu sobre o IED e a indissociável estratégia tecno-financeira das multinacionais de novo estilo, antes de alardear o sucesso de eventos desta natureza e o que isto poderá significar para as a universidade e para o direcionamento da produção do conhecimento no Brasil.

Destaca-se, nessa mesma conjuntura, a aprovação da Lei de Diretrizes e Bases da Educação Nacional (LDB) $n^{\circ}$ 9.394, em dezembro de 1996, impondo a contratação de um terço de doutores ou mestres em regime de dedicação integral para realizar pesquisa, preceito jurídico que impulsionou a pós-graduação no país, mais que dobrando o número de matrículas neste nível de formação.

Este fato justificava-se pela necessidade de formação de pesquisadores e da criação de um sistema de pós-graduação mais produtivo, regulado e flexível, para orientar e 
reorientar suas pesquisas e a produção de conhecimento, segundo a Agência Capes, responsável pelo controle e regulação desse sistema no país.

$\mathrm{Na}$ conjuntura da sanção da LDB, a Coordenação de Aperfeiçoamento de Pessoal de Nível Superior (Capes), fundada nos anos 1950 com o objetivo de capacitação do pessoal de ensino superior e que já se constituía, há décadas, em agência de avaliação da pós-graduação, acentuou sua função reguladora, que decorre do reordenamento, com o objetivo de organizar e reorganizar não somente os programas mediante seu modelo de avaliação, mas todo o sistema, tornando-se, assim, uma efetiva agência reguladora da pósgraduação brasileira. Vale dizer que estes traços recompõem o modelo de avaliação da Capes a partir de 1996/1997, modificando de forma estrutural a produção de conhecimentos nas instituições e em âmbito nacional.

É importante destacar aqui dois pontos: o primeiro consiste no formalismo abstrato da carreira do professor universitário contratado para o exercício da docência, pesquisa e extensão, mas que, em face da realidade atual das políticas públicas derivadas da reforma do Estado e da educação superior, vê-se compelido à complementação salarial e à ideologia do produtivismo acadêmico, produzida pela burocracia estatal e, hoje, um dos pilares centrais da cultura da instituição universitária.

O segundo ponto consiste em produzir a materialidade institucional para o que se chama produtivismo acadêmico em suas múltiplas formas de concretização: da produção de muitos artigos, seções de livros e livros, mas de forma mais acentuada na relação direta com o mercado. Esta ideologia do produtivismo acadêmico origina-se do Estado, com mediação da Capes e do CNPq, acrescidos da Financiadora de Estudos e Projetos (FINEP) e do Banco Nacional de Desenvolvimento Econômico e Social (BNDES), entre outros. O produtivismo acadêmico assume sua forma mais acabada, objetivada e cultural no Currículo Lattes (CV-Lattes). O Currículo Lattes consiste no portfólio de muitos doutores, formados depois de implantado o novo Modelo Capes de Avaliação, em 1996-1997, a correrem atrás de pós-doutoramentos, de publicações, de bolsas de produtividade, de participação em congressos bem classificados academicamente, isto no objetivo de fazer caminhar a "nova universidade", sem saberem bem para onde ela caminha.

Não existe uma reflexão sobre seu relacionamento com a instituição em que trabalha. Não há consciência de que o produtivismo acadêmico é uma ideologia pautada no pragmatismo, na utilidade e no economicismo, que leva à heterogestão institucional, tendo a geri-la, de um lado, o Estado, e, de outro, o mercado, predominantemente pela mediação do CNPq e da Capes.

O primeiro é um forte indutor de pesquisas aplicadas, enquanto a segunda é a agência reguladora da pós-graduação, que se torna o pólo irradiador da efetiva reforma universitária em curso. Em acréscimo, leva consigo as associações científicas, sempre muito prestigiadas por essas agências de regulação e fomento, realizando as políticas públicas do Estado e respondendo às demandas de conhecimento agregado para os produtos e processos de empresas nacionais e transnacionais.

Embora a produção de conhecimento seja de natureza imaterial, seu financiamento e os tempos e controles para sua realização são impostos pelo setor produtivo, e o produto de sua pesquisa aplicada será de pronto incorporado à instituição privada, tornando o seu trabalho e o resultado dele (a produção de conhecimento): imaterial, porém, produtivo. Esta é uma das razões pelas quais as corporações multinacionais, mais do que as de capital nacional, têm-se aproveitado de nossas universidades.

No Portal do CNPq/MCT, pode-se ler a manchete " $\mathrm{CNPq}$ firma parceria inédita para inclusão da inovação tecnológica nas empresas do Sistema Indústria”, com o seguinte conteúdo: 
O Ministro da Ciência e Tecnologia, Sergio Rezende, o presidente do Conselho nacional de Desenvolvimento Científico e Tecnológico (CNPq), Marco Antonio Zago, e o presidente da Confederação Nacional de Indústrias (CNI), Armando de Queiroz Monteiro, assinaram três protocolos de intenção para a promoção de projetos de inovação e tecnologias sociais no meio empresarial, durante a manhã desta quartafeira (05/03). Em seu discurso, o Ministro Sergio Rezende afirmou que esta é uma das tentativas da ciência brasileira em se aproximar do setor industrial. (BRASIL, 2008)

No âmbito do arcabouço jurídico legal, podemos citar como marcos regulatórios importantes que caracterizam a atual política de Ciência e Tecnologia, que amparam o discurso acima proferido pelo Ministro do MCT, na tentativa da ciência brasileira se aproximar do setor industrial: a criação dos Fundos Setoriais (1999); a Lei de Inovação Tecnológica (Lei Federal n 10.973 de 02.12.2004) que estabelece medidas de incentivo à inovação e à pesquisa científica e tecnológica no ambiente produtivo, com vistas à capacitação e ao alcance da autonomia tecnológica e ao desenvolvimento industrial do País; Lei 11.196/2005 conhecida como "Lei do Bem" que consolida incentivos fiscais para pessoas jurídicas, desde que realizem pesquisas tecnológicas e desenvolvimento de inovação tecnológica; Lei 8.958/94 que dispõe sobre as relações entre instituições federais de ensino superior e de pesquisa científica e tecnológica e as fundações de apoio; Lei 11.487/2007 que altera a Lei $n^{\circ} 11.196$, de 21 de novembro de 2005, para incluir novo incentivo à inovação tecnológica e modificar as regras relativas à amortização acelerada para investimentos vinculados a pesquisa e ao desenvolvimento; Lei $\mathrm{n}^{\circ} 11.079 / 2004$ que institui normas gerais para licitação e contratação de parceria público-privado no âmbito da administração pública.

Os marcos regulatórios demonstrados acima, possibilitados pela reforma do Estado e pela inclusão da universidade no setor de serviços não exclusivos do Estado, nos apontam para uma nova concepção de ciência e para a tendência da pesquisa cientifica, sobretudo, na universidade pública.

Para efeito de entendimento do aparente processo de mercantilização da esfera educacional delineando, por meio do Estado, na tabela 1 consta o total de investimentos realizado pelo $\mathrm{CNPq}$ no período de 1996-2008 nas modalidades Bolsas e fomento a pesquisa. Uma breve análise da tabela 1 permite notar tendências. $\mathrm{O}$ fomento de bolsas tende a diminuir e o percentual de participação da categoria fomento à pesquisa tende aumentar no período analisado. Isto parece demonstrar que estaria havendo uma inversão nos investimentos realizados pelo $\mathrm{CNPq}$, onde há uma diminuição no fomento de investimentos no processo formativo básico, por meio de bolsas, principalmente quando relacionado ao aumento na década de 1990 de programas de Pós-graduação no país e a necessidade da construção do corpo docente necessário para a criação de novos programas. E ainda a partir de 2007 e 2008 verificamos um aumento no fluxo de recursos para fomento à pesquisa, indicando sustentável hipótese de que no Brasil a formação de pesquisadores teria chegado a um nível equilibrado e satisfatório para dar impulso aos programas de pós-graduação. O momento conjuga, na verdade, os dois movimentos, formação de pesquisadores para manter trabalhadores de alta qualificação como exército de reserva, por um lado, por outro, expansão do fomento para os pesquisadores mais experimentados. Outrossim, observa-se que as bolsas no exterior mantém-se quando considerada a sua ordem de grandeza em face da necessidade das atualizações de demanda 
rapidamente postas por meio da economia em nível planetário, que se interpõe na pauta de pesquisa da instituição universitária e fazem da sua autonomia apenas um fetiche.

Tabela 1

CNPq - Total dos investimentos realizados em bolsas e no fomento à pesquisa - 1996-2008

\begin{tabular}{|c|c|c|c|c|c|c|c|c|}
\hline \multirow[b]{3}{*}{ Ano } & \multicolumn{6}{|c|}{ Investimentos em $\mathrm{R} \$$ mil correntes } & \multirow{2}{*}{\multicolumn{2}{|c|}{ Participação \% }} \\
\hline & \multirow[b]{2}{*}{$\begin{array}{c}\text { Bolsas no } \\
\text { país (1) }\end{array}$} & \multirow[b]{2}{*}{$\begin{array}{l}\text { Bolsas no } \\
\text { exterior }\end{array}$} & \multirow[b]{2}{*}{$\begin{array}{c}\text { Subtotal } \\
\text { Bolsas }\end{array}$} & \multirow[b]{2}{*}{$\begin{array}{l}\text { Fomento à } \\
\text { pesquisa (2) }\end{array}$} & \multicolumn{2}{|c|}{ Total } & & \\
\hline & & & & & Total & Var.\% & Bolsas & $\begin{array}{l}\text { Fomento } \\
\text { à } \\
\text { pesquisa }\end{array}$ \\
\hline 1996 & 431.631 & 41.944 & 473.575 & 61.015 & 534.590 & - & 89 & 11 \\
\hline 1997 & 411.825 & 29.839 & 441.664 & 71.451 & 513.115 & -4 & 86 & 14 \\
\hline 1998 & 354.523 & 26.784 & 381.307 & 44.583 & 425.890 & -17 & 90 & 10 \\
\hline 1999 & 337.747 & 26.849 & 364.596 & 76.457 & 441.053 & 4 & 83 & 17 \\
\hline 2000 & 353.831 & 24.406 & 378.237 & 115.797 & 494.034 & 12 & 77 & 23 \\
\hline 2001 & 367.399 & 43.176 & 410.575 & 170.645 & 581.221 & 18 & 71 & 29 \\
\hline 2002 & 377.944 & 55.674 & 433.618 & 165.055 & 598.673 & 3 & 72 & 28 \\
\hline 2003 & 429.657 & 40.275 & 469.932 & 181.258 & 651.190 & 9 & 72 & 28 \\
\hline 2004 & 535.360 & 37.352 & 572.712 & 221.485 & 794.197 & 22 & 72 & 28 \\
\hline 2005 & 576.255 & 30.471 & 606.727 & 242.543 & 849.270 & 7 & 71 & 29 \\
\hline 2006 & 645.902 & 25.285 & 671.186 & 232.229 & 903.415 & 6 & 74 & 26 \\
\hline 2007 & 682.551 & 31.609 & 714.159 & 477.379 & 1.191 .538 & 40 & 60 & 40 \\
\hline 2008 & 747.730 & 32.290 & 780.020 & 423.554 & 1.203 .575 & 33 & 65 & 35 \\
\hline
\end{tabular}

Fonte: CNPq/AEI.

Vale à pena lembrar-se de Luiz Carlos Bresser Pereira e das principais instituições que pertenceriam ao setor de serviços não-exclusivos do Estado ou competitivos: as universidades, as escolas técnicas, os hospitais universitários e os museus. Os protocolos assinados contemplam as universidades e escolas técnicas. É necessário também destacar a direção e os objetivos da educação básica e da profissional de nível técnico posicionada entre o Estado e o mercado. Vê-se a materialidade social e política do Estado brasileiro ao criar um programa indutor dos ativos intangíveis, como observa Michalet (1985), já comentado anteriormente.

Em matéria da revista Desafios do desenvolvimento (LULA, 2008, p. 47), pode-se ler que o "governo e a indústria brasileiros querem corrigir os erros do passado com uma arrojada estratégia de inovação que permita maior competitividade e internacionalização das empresas nacionais". No entanto, segundo pesquisadores do Instituto de Pesquisas Econômicas Aplicadas (IPEA):

Embora muito dinheiro tenha entrado no país por conta das empresas nacionais, as empresas locais da mesma cadeia produtiva aproveitam muito pouco as oportunidades de troca de informações e tecnologia. [...] as filiais estrangeiras são as que mais aproveitam as políticas públicas para ampliar conhecimento (LULA, 2008, p. 47).

Ainda segundo matéria da revista Desafios do Desenvolvimento (LULA, 2008, p. 48), "a meta do governo federal é elevar a taxa de investimento, hoje, de 1,02\% do Produto Interno Bruto (PIB), para 1,5\% até 2010”. Isto é o uso do fundo público em favor do capital nacional e mundial. Segundo a política de comércio e indústria do país, o uso do fundo público está voltado para o aumento do capital produtivo para lastrear o capital financeiro. Aqui, podem-se perceber as mediações entre a financeirização e o aumento do capital produtivo no âmbito planetário. 
Ao lado da Lei de Inovação existe a chamada Lei do Bem, sancionada em 2005, que garante "incentivos fiscais a quem aposta na pesquisa, como a dedução dos gastos no pagamento de Imposto de Renda da Pessoa Jurídica" (LULA, 2008, p. 53), e da Contribuição Social sobre Lucro Líquido. Destaca-se que, embora segundo os pesquisadores Ipea a relação entre a academia e o setor produtivo seja um processo lento, já se pode observar um movimento positivo na direção da aproximação destas duas esferas quando se analisa o número de empresas que se vêm envolvendo neste processo, bem como os valores investidos. Segundo Marcio Wohlers de Almeida, do MCT, entre "2005 e 2006, após a implantação da Lei do Bem, o número de empresas que investiram em P\&D saiu de 36 para 127. O montante de recursos privados empregados saltou de R $\$ 214,9$ milhões para R\$2,0 bilhões." (LULA, 2008, p. 53)

Como se pode notar do que se expôs até este momento, todas as ações políticas colocam o fundo público com o objetivo de aumentar a produtividade brasileira e, com isto, o capital produtivo mundial. Isto parece dar-se predominantemente por meio de ciência, tecnologia e inovação (CT\&I), segundo a política industrial do MCT e do Ministério de Desenvolvimento, Indústria e Comércio Exterior. Por estes dois ministérios o Estado coloca a universidade como ponta-de-lança no crescimento econômico competitivo e exportador, eventualmente incentivando a transnacionalização das indústrias nacionais sob controle brasileiro. Para isto, não mede esforços em usar o fundo público nessa empreitada e em mudar profundamente as estruturas sócio-históricas da universidade pública e da produção do conhecimento da universidade pública.

Isto implica dizer que a universidade está profundamente mudada em suas estruturas e autonomia. Formas de gestão político-institucionais estão postas desde seu exterior, bem como a avaliação se realiza por resultados e sua acreditação, pela "relevância de sua pauta de pesquisa". Há três principais movimentos de reconfiguração da pósgraduação no país: 1) o CNPq (Estado) e seus convênios e editais indutores de pesquisa aplicada em busca da produtividade do capital; 2) a Agência Capes (Estado), que regula um sistema de pós-graduação e cada programa com o mesmo objetivo do $\mathrm{CNPq}$, e 3) o mercado, para o qual convergem os movimentos anteriores e que, em última instância, conduz a reforma universitária. Aqui, como define Bourguinat a estratégia tecno-financeira e as vantagens não-econômicas do IED ficam nuas.

Como se procurou mostrar, o Estado reorganiza a pós-graduação de forma mediada pela Capes e pelo CNPq. Estas agências buscam, de forma articulada, fazer da pesquisa um elemento central para a produção de um conhecimento orientado para a valoração do capital. No âmbito social, por meio de programas focais. Porém, quando se trata do setor produtivo, o fundo público naturalizado pelo capital busca produzir novas tecnologias de processo e de produto que agreguem mais valor aos produtos que serão comercializados no mercado internacional ou nacional. Este processo transcende a produção e tem em seu centro as relações que as empresas multinacionais de novo estilo estabelecem com outras empresas, bancos, agências multilaterais, Estados e instituições estatais, neste caso particular, as universidades.

Em face disso, a educação é demandada pelo capital a reformar-se, assim como e primeiramente o Estado nacional. Para o que se está analisando, a pós-graduação passa a ocupar o espaço central e mais relevante para o Estado, posto que, no país, o lugar em que o conhecimento é desenvolvido com maior consistência é o dos níveis pós-graduados das universidades.

Diversamente do que ocorria à época de Marx, o trabalho imaterial torna-se gradativamente mais produtivo, o que significa que CT\&I tornam-se cada vez mais imprescindíveis à potencialidade renovada de fantástica ampliação da riqueza a partir da 
base industrial consolidada pela estrutura produtiva existente. As universidades são postas no centro do processo de formação de professores e de produção de CT\&I. Nesse contexto, modifica-se profundamente a natureza das instituições e a produção do conhecimento. No pólo antitético a esse, surge uma demanda reformista trazida pela própria substância histórica do capitalismo. No plano da economia, emerge a necessidade de um processo contínuo de ensino e aprendizagem, como se pode observar na Declaração mundial sobre educação para todos, de 1990 (ORGANIZAÇÃO DAS NAÇÕES UNIDAS PARA A EDUCAÇÃO, A CIÊNCIA E A CULTURA, 1990).

É preciso compreender determinadas funções de uma universidade privada, mas a grande preocupação deve residir na compreensão da universidade pública. A reforma do aparelho do Estado, de Pereira, produziu uma nova dimensão no Estado, por onde vaza o público, fato que fertiliza o novo paradigma de produção do conhecimento e promove a mudança na identidade da instituição universitária pública.

Diante do acima exposto, é possível ao menos inferir que o processo de mercantilização da universidade pública brasileira e de sua identidade institucional tem sua origem na pós-graduação, reorganizada especialmente pela Capes e pelo $\mathrm{CNPq}$, tendo como finalidade o mercado e a resolução focal dos problemas sociais. A compreensão desse evento como um processo de controle e regulação sociais, com origem no Estado reformado, em articulação com a mundialização do capital, processo que terminou como alvo da naturalização do fundo público pelo capital e resultou em reformas das instituições republicanas brasileiras. A universidade é uma das instituições centrais para a objetivação desta insidiosa e profunda mudança na cultura brasileira.

\section{Referências}

BRESSER PEREIRA, L.C. Crise econômica e reforma do Estado no Brasil - para uma nova interpretação da América Latina. São Paulo: Editora 34, 1996.

- Gestão do setor público: estratégia e estrutura para um novo Estado. In: PEREIRA, Luiz Carlos Bresser Pereira; SPINK, Peter. Reforma do Estado $e$ Administração pública Gerencial. $2^{\circ}$ ed. Rio de Janeiro, Editora Fundação Getúlio Vargas, 1998. p.21-38.

CHESNAIS, F. A mundialização do capital. São Paulo: Xamã Editora, 1996.

CONSELHO NACIONAL DE DESENVOLVIMENTO CIENTÍFICO E TECNOLÓGICO. CNPq memória. Disponível em: http://centrodememoria.cnpq.br. Acesso em: 30 de maio de 2008.

LULA, E.. O Caminho do Crescimento. Desafios do Desenvolvimento, Brasília, ano, 5, n, 42. p. 46-51, abr. 2008.

MICHALET, C, A. Les multinationales face à la crise. IRM, Lausanne, 1985.

SILVA JR, João dos Reis. Reforma do Estado e da Educação no Brasil de FHC. São Paulo: Xamã, 2002. 
SILVA JÚNIOR, João dos Reis.; SGUISSARDI, Valdemar. As novas faces da educação superior no Brasil - reforma do Estado e mudança na produção. $2^{\mathrm{a}}$ ed. São Paulo: Cortez Editora; Bragança Paulista: EDUSF, 2001.

Trabalho intensificado nas federais: pós-graduação e produtivismo econômico. São Paulo: Xamã Editora, 2009.

\footnotetext{
${ }^{\text {i }}$ Disponível em: http://www.fazenda.gov.br/. Acesso em: 14 abr. 2003.
}

Artigo recebido em: 05/03/2010

Aprovado para publicação em: 09/04/2010 